\title{
EL TRÁFICO VESICULAR Y COMPAÑÍA: CAMBIANDO PERSPECTIVAS
}

\section{VESICULAR TRAFFIC AND COMPANY: CHANGED PERSPECTIVES}

\author{
Anayetzin Torres-Rivera ${ }^{1}$ \\ Fecha de recepción: 28 de noviembre de 2016 \\ Fecha de aceptación: 10 de octubre de 2017
}

Resumen - A partir de la década de los ochenta, la concepción en las funciones de las vesículas celulares y las vías que transitan para comunicar a las células ha cambiado de ser meras transportadoras de desechos a ser moléculas indispensables en su desarrollo y supervivencia, al ser vehículos que transportan proteínas, lípidos y material genético que puede modificar por completo la fisiología y metabolismo de la célula receptora, lo cual abre una espectro amplio de uso en aplicaciones clínicas y terapéuticas.

\section{Palabras clave:}

Vesículas extracelulares, exosomas, microvesículas, comunicación intercelular.
Abstract - Since 80's decade, the notion about cellular vesicles functions and the mechanisms that they follow in the cell and the organism has changed, from simple waste carriers to communicating molecules essential for the development and survival of the cell. Vesicles are able to transport proteins, lipids and genetic material involved in the physiologic and metabolic transformation of the target cell, and thus, they use in clinic and therapeutic applications could bring many benefits in the future.

\section{Keywords:}

Extracellular vesicles; exosomes, microvesicles, intercellular communication. 
$\theta$ n el año 2013, los investigadores Randy W. Schekman, James E. Rothman y Thomas C. Südhof obtuvieron el Premio Nobel de Medicina "por sus descubrimientos de la maquinaria que regula el tráfico vesicular, el principal sistema de transporte de nuestras células", lo cual significó un gran respaldo hacia el conocimiento generado y obtenido a partir de la década de los 40 sobre las partículas y los procesos que gobiernan el tránsito y circulación de diversas moléculas al interior de las células y que sirven, además, en los procesos de comunicación intercelular, permitiendo el correcto funcionamiento de los organismos y su supervivencia (Van der Pol, Böing, Harrison, Sturk y Nieuwland, 2012; Meguías, Molist y Pombal, 2014; Szatanek, Baran, Siedlar, Baj-Krzyworzeka, 2015).

En un inicio, los estudios sobre las vesículas celulares reducían el desempeño de éstas a la remoción de desechos celulares. No obstante, en el caso de las células eucariotas, al ser compartamentalizadas, la función de las vesículas comenzó a revisarse y se encontró que ostentaban un papel fundamental en la comunicación entre cada uno de los organelos, al llevar en su interior, o incluidas en sus membranas, las moléculas que permitirían la siguiente fase del proceso celular, como es el caso del retículo endoplásmico rugoso con el aparato de Golgi, el retículo endoplásmico y la mitocondria o recientemente, como se ha detectado, la comunicación por vesículas entre mitocondrias con los peroxisomas (Meguías et al., 2014; Sugiura, McLelland, A Fon y McBride, 2014).

Sin embargo, las rutas que siguen las vesículas y su contenido no se limitan a los orgánulos intracelulares, ya que además son capaces de hacer una trayecto exportador (exocitosis) e importador (endocitosis) a través de la membrana plasmática, que es esencial para el intercambio de biomoléculas, receptores celulares e información genética entre las células, lo cual tiene influencia sobre la fisiología, el metabolismo y la patogenia de la célula receptora, y en su conjunto conforman el mecanismo denominado tráfico vesicular (Ohno,
Ishikawa y Kuroda, 2013; Van der Pol et al., 2012; Meguías et al., 2014). Este descubrimiento llevó a la reinterpretación de los procesos de comunicación intercelular que anteriormente eran descritos mediante modelos de interacción directa célula-célula o de secreción de moléculas solubles requeridas para la función esperada (Van der Pol et al., 2012; Raposo y Stoorvogel, 2013; Szatanek et al., 2015). Ahora se sabe que el desempeño de las vesículas no se limita a la comunicación célula-célula, sino que además está implicada en la señalización celular, la presentación de antígeno, en la inmunosupresión, en la propagación de los agentes infecciosos, en la adhesión celular y la coagulación, en la integridad y función vascular, así como en la angiogénesis, desarrollo y metástasis de células cancerosas (Van der Pol et al., 2012).

Es la variedad de funciones descubiertas para las vesículas celulares la que ha generado un cambio en el panorama acerca de su importancia y aplicabilidad para el estudio y entendimiento de diversas patologías; además de abrir nuevas posibilidades en el diagnóstico y tratamiento de algunas enfermedades (Minciacchi, Freeman y Di Vizio, 2015; Ohno et al., 2013; Raposo y Stoorvogel, 2013; Szatanek et al., 2015; Van der Pol et al., 2012).

Un primer abordaje dentro del estudio del tráfico vesicular es la determinación de la variedad de vesículas que la célula forma para su exportación, de tal manera que se ha clasificado más de una decena de ellas usando como criterios su biogénesis, el tamaño, la densidad, el contenido molecular (proteico o de ácidos nucleicos), las proteínas de superficie e inclusive las diversas metodologías empleadas actualmente para aislarlas. Lo anterior ha generado una nomenclatura muy diversa que las designa como micropartículas, microvesículas, exosomas, ectosomas, dexosomas, prostasomas, exovesículas, nanovesículas, oncosomas, entre otras. En muchas ocasiones dichos nombres describen al mismo tipo de partícula, por lo que actualmente todas se engloban bajo el término 
simplificado de "vesículas extracelulares", a fin de evitar confusiones en el intercambio de información en las diversas investigaciones, ya que hasta el momento no existe un consenso para agruparlas debido a que el tamaño de muchas de ellas se sobreponen, comparten moléculas de superficie (como las tetraspaninas; Minciacchi et al, 2015) o en algunos casos tienen el mismo origen: la liberación a partir de la membrana plasmática (Minciacchi et al, 2015; Raposo y Stoorvogel, 2013; Van der Pol, Böing, Gool y Nieuwland, 2016). Mención aparte merecen los cuerpos apoptóticos que, si bien se originan como prolongaciones de la membrana plasmática y tienen tamaños similares a varios tipos de vesículas extracelulares, los mecanismos de creación y los estímulos que los activan son diferentes a los vesiculares y no serán abordados en esta revisión.

A pesar de esta gama, el estudio de las vesículas extracelulares se ha enfocado principalmente en dos variedades de partículas: las microvesículas y los exosomas, debido sobre todo a su aplicabilidad en el estudio de diversas enfermedades y a la forma en que son aisladas e identificadas (Ohno et al., 2013; Raposo y Stoorvogel, 2013; Szatanek et al., 2015; Van der Pol et al., 2012).

Los exosomas son partículas muy pequeñas, de un diámetro aproximado de 30 a 100 nm, con una densidad aproximada de 1.13 a $1.19 \mathrm{~g} / \mathrm{mL}$ medido en un gradiente de sacarosa. Surgen por invaginación en las vesículas intraluminales localizadas dentro de los cuerpos multivesiculares. Dichas estructuras forman parte del Complejo de Clasificación Endosómica Requerido para el Transporte (o ESCRT, por sus siglas en inglés), que es el responsable de liberar a los exosomas y además de aportarle proteínas como Alix y TSG101 (tumor susceptibility gene 101). Además, por su origen endosomal, los exosomas enriquecen su superficie con proteínas como flotilina, anexinas y tetraspaninas (CD63, CD9, CD81), las cuales sirven como moléculas identificadoras junto con algunas proteínas de choque térmico (HSP70 y HSP90) y las del ESCRT.
Los exosomas son generalmente aislados por ultracentrifugación, usando velocidades de 100000 a 200000 g (Raposo y Stoorvogel, 2013; Szatenek et al., 2015; Van der Pol et al., 2012; Van der Pol et al., 2016).

Las microvesículas, conocidas también como micropartículas, ectosomas o vesículas de mudanza, son partículas con un diámetro promedio de 100 a 1000 nm que se generan directamente en la membrana plasmática a partir de brotes salientes específicos provocados por la activación de la célula, en respuesta a un estímulo exterior (Ohno et al., 2013). Su mecanismo de formación supone que después de que la célula ha sido activada por un estímulo, por ejemplo la oxidación de componentes celulares por especies reactivas de oxígeno/nitrógeno y radicales, o la liberación de citocinas o endotoxinas, la concentración de calcio en el citosol se incrementa, permitiendo la activación de diversas enzimas (como las calpaínas y las cinasas) y la inhibición de otras (como las fosfatasas y las traslocasas), que dan paso a la remodelación del citoesqueleto, lo que se traduce en una asimetría de la membrana que provocará una ampolla o burbuja de la que se desprenderá la microvesícula en cuestión. Este tipo de vesículas extracelulares son ricas en integrinas, selectinas y tetraspaninas específicas de la célula origen.

Por su variabilidad, la densidad de las microvesículas es desconocida y suelen aislarse por centrifugación en un intervalo de 10000 a 20000 g (Raposo y Stoorvogel, 2013; Szatenek et al., 2015; Van der Pol et al., 2012; Van der Pol et al., 2016).

A pesar de que la centrifugación a diferentes velocidades o los gradientes de sacarosa han sido los técnicas más usadas en los laboratorios de investigación para el estudio de las vesículas extracelulares, existen otras metodologías empleadas para su aislamiento, como la inmunoafinidad usando anticuerpos monoclonales embebidos en perlas magnéticas, columnas de exclusión molecular o la precipitación polimérica (Raposo y Stoorvogel, 2013; Szatenek et al., 2015; Van der Pol et al., 2012; Van der Pol et al., 2016; Witwer, Buzás, Bemis, Bora, Lässer, 
Lötvall, Nolte-'t Hoen, Piper, Sivaraman, Skog, Théry, Wauben y Hochberg, 2013).

Mención aparte merecen los métodos de identificación de vesículas extracelulares, los cuales también representan un reto en la estandarización y la futura aplicabilidad de las vesículas en terapias o diagnósticos. Las técnicas empleadas son una combinación entre citometría de flujo, rastreo de nanopartículas, western blot, microscopía electrónica, espectroscopia de Ranman e inclusive la microscopía de fuerza atómica, con los que se pretende conocer el tamaño, la concentración, la integridad y el origen de las vesículas extracelulares (Raposo y Stoorvogel, 2013; Szatenek et al., 2015; Van der Pol et al., 2012; Van der Pol et al., 2016; Witwer et al., 2013).

Un segundo abordaje en el estudio del tráfico vesicular consiste en obtener y reconocer el contenido de las vesículas extracelulares, con la finalidad de entender el impacto que puede tener este cargamento en la célula receptora. Los estudios de proteómica, metabolómica y genómica demuestran que es altamente heterogéneo, que puede incluir proteínas de superficie o citosólicas, ácidos nucleicos y lípidos. Dicho contenido está claramente influenciado por el tipo celular, la condición fisiológica o patológica y el tipo de estímulo que genera y libera a la vesícula extracelular; por ejemplo, se sabe que estas vesículas secretadas en algunos carcinomas llevan microARN o ARN de interferencia que favorecen la angiogénesis y metástasis. También se han observado vesículas extracelulares de células cancerosas que participan en la transferencia de proteínas oncogénicas a células sanas, como es el caso del receptor EGFRvill, transferido directamente de las vesículas extracelulares derivadas del tumor hacia las células blanco. Están, además, las involucradas en la supresión de la respuesta inmune al inactivar linfocitos T y células Natural Killers mediante el factor TFG $\beta 1$ contenido en exosomas de tumor, o las que participan en la regulación de la diferenciación de los linfocitos $T$ y células mieloides. El contenido vesicular también ha sido estudiado en la acumulación de placas amiloides en el Alzheimer por acción de $\beta$-secretasas localizadas en exosomas, así como en la hipótesis del "exosoma de Troja", donde miARNs del contenido vesicular coadyuvan en la actividad invasiva y de replicación de varios retrovirus como el HIV, en el herpesvirus tipo 6, el virus de hepatitis C y el virus de Epstein-Barr. Inclusive, ahora se postula a los exosomas como un posible mecanismo de dispersión de priones de células infectadas del tracto gastrointestinal hacia otras del sistema nervioso (Minciacchi et al., 2015; Ohno et al., 2013; Van der Pol et al., 2012). La información sobre el contenido vesicular en proteínas, ácidos nucleicos y metabolitos se encuentra reunida en dos principales bases de datos: Exocarta y Vesiclepedia (Kalra et al, 2012; Keerthikumar et al., 2015).

Es importante hacer notar que los cambios en la cantidad liberada de microvesículas y/o exosomas respecto de controles también representa un posible marcador de enfermedad, independientemente del contenido que lleven. Lo anterior se ha mostrado en algunos estudios sobre vesículas extracelulares en entidades patológicas como el cáncer de próstata o la preeclamsia, en los que se ha reportado un incremento en el número dichas vesículas; pero los resultados revelaron que la cantidad de vesículas extracelulares en muestras de pacientes no sólo son un marcador de inicio, sino también sirven para determinar la progresión de la enfermedad, ya que su presencia y concentración constituyen en sí una diferencia en dos momentos distintos de la célula (Ohno et al., 2013; Van der Pol et al., 2012).

Asimismo, es indispensable resaltar que las vesículas extracelulares, al ser moléculas que se secretan, han podido ser aisladas de diversos fluidos corporales, como sangre, orina, ascitis, saliva, líquido cefalorraquídeo, semen, líquido amniótico, bilis, etcétera, lo que las hace potenciales blancos terapéuticos o marcadores diagnósticos, lo cual representa un reto, pues cada fluido presenta características especiales a considerar en el momento del aislamiento de las vesículas, las cuales podrían contaminarse con otras partículas propias del 
fluido (como las LDL o HDL) o agregados proteicos u obtener poca muestra por el reducido volumen que se produce en el cuerpo (Raposo y Stoorvogel, 2013; Van der Pol et al., 2012; Witwer et al., 2013).

A pesar de los múltiples estudios que en las últimas tres décadas se han hecho acerca del tráfico vesicular y las vesículas extracelulares, existen muchos aspectos sobre la función fisiológica, el papel en la patología de diversas enfermedades y en los mecanismos moleculares que gobiernan que no han sido dilucidados. Es seguro que no se han identificado completamente todas las funciones que pueden ejercen las vesículas extracelulares, para lo cual será indispensable mejorar y estandarizar las metodologías de aislamiento y caracterización, así como lograr un consenso en la nomenclatura de las mismas que favorezca la comparación de los resultados de los diferentes estudios (Raposo y Stoorvogel, 2013; Szatenek et al., 2015; Van der Pol et al., 2012; Witwer et al., 2013).

\section{Referencias}

Kalra, H., Simpson, R. J., Ji, H., Aikawa, E., Altevogt, P., Askenase, P., Bond, V. C., Borras, F. E. et al. (2012). Vesiclepedia: A compendium for extracellular vesicles with continuous community annotation. PLoS Biology, 10(12), e1001450. Recuperado de https://doi. org/10.1371/journal.pbio.1001450

Keerthikumar, S., Chisanga, D., Ariyaratne, D., Al Saffar, H., Anand, S., Zhao, K., Samuel, M., Pathan, M., Jois, M., Chilamkurti, N., Gangoda, L. y Mathivanan, S. (2015). ExoCarta: A web-based compendium of exosomal cargo. Journal of Molecular Biology, 428(4), 688-692.

Meguías, M., Molist, P. y Pombal, M. A. (2014). Atlas de Histología vegetal y animal: Tráfico vesicular. Universidad de Vigo: Facultad de Biología.Recuperado de https:// mmegias.webs.uvigo.es/5-celulas/5-trafico.php

Minciacchi, V. R., Freeman, M. R. y Di Vizio, D. (2015). Extracellular Vesicles in Cancer: Exosomes, Microvesicles and the Emerging Role of Large Oncosomes. Semin. Cell Dev. Biol., 40, 41-51.

Ohno, S., Ishikawa, A. y Kuroda, M. (2013). Roles of exosomes and microvesicles in disease pathogenesis. Adv. Drug Delivery Rev., 65(3), 398-401.

Raposo, G. y Stoorvogel, W. (2013). Extracellular vesicles: Exosomes, microvesicles, and friends. J. Cell Biol,, 200(4), 373-383.

Sugiura, A., McLelland, G., A Fon, E. y McBride, H. (2014). A new pathway for mitochondrial quality control: mitochondrial-derived vesicles. EMBO Journal, 33(19), 2143-2156.

Szatanek, R., Baran, J., Siedlar, M., Baj-Krzyworzeka, M. (2015). Isolation of extracellular vesicles: Determining the correct approach (Review). International J. Mol. Med., 36(1), 11-17.

The Nobel Prize in Physiology or Medicine 2013. Recuperado de https://www.nobelprize.org/nobel_ prizes/medicine/laureates/2013/

VanDer Pol, E., Böing, A., Harrison, P., Sturk, A. y Nieuwland, R. (2012). Classification, functions, and clinical relevance of Extracellular vesicles. Pharmacological Reviews, 64, 676-704.

Van Der Pol, E., Böing, A. N., Gool, E. L. y Nieuwland, R. (2016). Recent developments in the nomenclature, presence, isolation, detection and clinical impact of extracellular vesicles. J. Thromb. Haemost, 14(1), 48-56.

Witwer, K. W., Buzás, E. I., Bemis, L. T., Bora, A., Lässer, C., Lötvall, J., Nolte-'t Hoen, E. N., Piper, M. G., Sivaraman, S., Skog, J., Théry, C., Wauben, M. H. y Hochberg, F. (2013). Standardization of simple collection, isolation and analysis methods in extracellular vesicle research. J Extracellular Vesicles, 2, 20360-20385. 


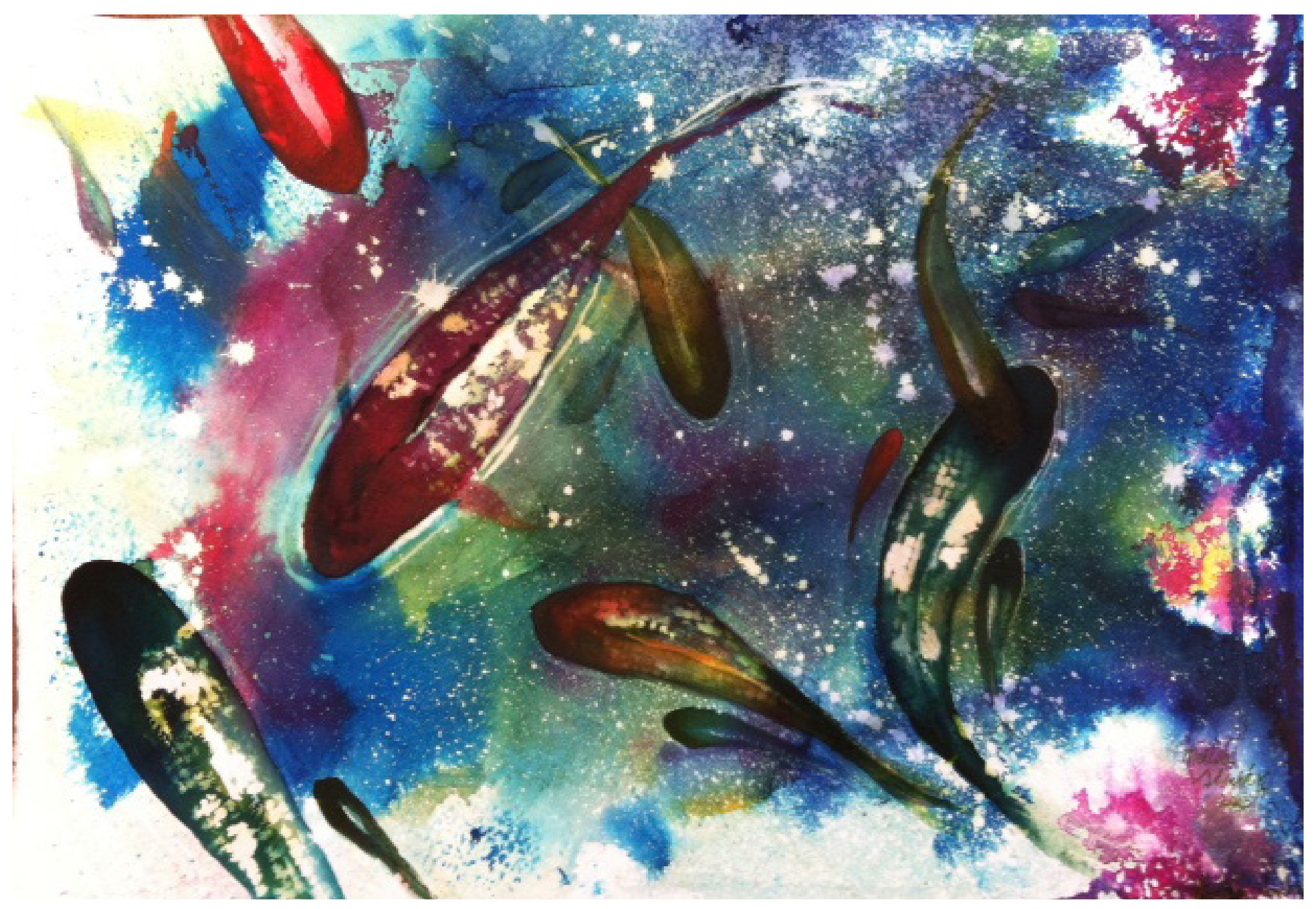

Melisa Sánchez Méndez.

"Prusia",

Mixta/papel,

$25 \times 35 \mathrm{~cm}$,

2016. 